\title{
Respiratory ill health among coal miners and telecommunication workers in south Wales
}

\author{
M H LLOYD, S J GAULD, AND C A SOUTAR \\ From the Institute of Occupational Medicine, Edinburgh EH8 9SU, UK
}

ABSTRACT As part of a large cross sectional epidemiological study of respiratory disease in coalminers, the respiratory health of miners in one colliery in south Wales has been compared with the health of nearby telecommunication (telecom) workers. The studies were carried out in 1981 and 1982. The answers to questionnaires on respiratory symptoms and results of lung spirometry indicate a much greater frequency of respiratory ill health among the miners than the telecom workers. The frequency of symptoms of chronic bronchitis among the current employees was $31 \%$ in the miners and 5\% in the telecom workers, and these symptoms were reported as frequently by younger as by older miners. Reports of other respiratory symptoms showed similarly large differences between current miners and telecom workers. These differences were seen both within non-smoking and smoking groups. Comparisons of $\mathrm{FEV}_{1}$ with predicted values (several different predictions were used) confirmed that the differences in reported symptoms were accompanied by

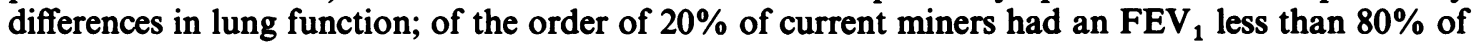
predicted compared with $10 \%$ of current telecom workers. The excess of respiratory disease shown among these miners is not necessarily a consequence of the dust concentrations currently experienced underground, nor is the colliery necessarily representative of the coal industry generally. The findings, however, indicate the continued need for measures to improve the respiratory health of these men.

Many studies of respiratory disease in British coalminers have shown an excess of chronic bronchitis and lower levels of lung function than in comparable groups. ${ }^{1-6}$ The data for the most recent of these studies was collected in 1966, the least recent in 1949. Much debate centred on whether this excess of respiratory disease was related to occupation or to other social differences. Subsequently the likelihood of having persistent productive cough, ${ }^{78}$ of having a low $F V_{1},{ }^{9-12}$ and of suffering excessive loss of FEV over a period ${ }^{13}$ was shown to be influenced by a man's cumulative lifetime exposure to respirable dust, confirming that occupational exposure contributed to the excess of respiratory disease in coalminers.

In 1970 a new standard for the control of respirable dust in British mines was introduced by the National Coal Board, in the context of prevention of pneumoconiosis, and new regulations were introduced in $1975^{14}$ and again in $1978 .^{15}$ Concentrations of air-

Accepted 23 July 1985 borne respirable dust have been reduced progressively in British coalmines since $1970,{ }^{16}$ and this has resulted in a reduction of the incidence of pneumoconiosis to about one third of that before $1970 .{ }^{17}$ In view of these changes, and likely improvements in social conditions occurring over the past few decades, the general respiratory health of miners might be expected to have improved.

We are at present conducting cross sectional epidemiological studies of selected miners from three collieries in Britain to establish among other things whether exposure to the respirable dust concentrations current in British mines still contributes to respiratory disease in exposed miners. The surveys are still in progress, but we are currently analysing the results from the first colliery, in south Wales. The differences in frequencies of respiratory disease between the miners at this colliery and a neighbouring group of male telecommunications (telecom) workers are sufficiently striking to prompt us to report these findings in advance of a detailed analysis of the possible causes of respiratory disease. 


\section{Subjects and methods}

The study samples were selected from men who had worked at any time between January 1970 and August 1981 at one colliery in south Wales and at a nearby telecommunications establishment employing men who installed and maintained telephone equipment, mainly out of doors. Records of 1589 miners fulfilling the criteria were available; 602 were still working at the colliery in 1981, 987 had left. The corresponding figures for the telecom workers were 1794, of whom 1004 were current employees and 790 had left. The colliery had participated for 26 years in the pneumoconiosis field research of the National Coal Board, and estimates of cumulative exposure to respirable dust up to 1979 were available for each man who had worked at the colliery. These estimates were used for the selection of men. The dust exposure data are currently being up-dated, however, and are not used in the analyses presented here. The miners were selected randomly within six ten year age ranges and from ranges of dust exposure. Since the purpose of the study was to examine the effects of dust exposure and other factors on lung function, higher proportions of the men in the older age and higher dust exposure groups were selected. Current men and leavers were selected separately up to a total of 387 current men and 371 leavers. Telecom workers were selected randomly by similar age criteria, though not of course by dust exposure, up to totals of 248 current men and 246 leavers. No men under 25 were included since the lungs may continue to grow up to this age.

The men selected were invited by letter to take part in the research. The addresses of those who had left each industry were obtained from employment and pension records and union and concessionary coal records. Men agreeing to take part were seen by appointment during 1981 and 1982 in mobile survey units at the colliery and telecom depot. Second letters of invitation were sent to men not replying to the first, and during the survey home visiting and other local search procedures were carried out to attempt to contact men still not replying.

At the medical survey each man answered the MRC questionnaire of respiratory symptoms and smoking habit, ${ }^{18}$ with supplementary questions; and trained personnel took occupational histories. Full size chest radiographs were taken and read for clinical purposes by a physician experienced in the radiographic classification of pneumoconiosis, who at the same time also recorded his interpretation of the appearances according to the ILO classification ${ }^{19}$ of the appearances of pneumoconiosis. These classifications were used to identify radiographs showing the large opacities of progressive massive fibrosis (PMF).

Lung function was measured by recording at least three forced expiratory flow volume curves using an Ohio 800 electronic spirometer on to a fast response XY recorder (Hewlett Packard model 70451). The $\mathrm{FEV}_{1}$ value was calculated from each technically satisfactory curve, and the mean value was used foro analysis. Height and weight were measured in a $\frac{\overline{\bar{D}}}{\overline{\bar{n}}}$ standard manner.

For the purpose of the analysis, men were grouped $\frac{\widehat{\Phi}}{\Omega}$ according to their answers to the questionnaire into four smoking categories: lifelong non-smokers, ex- smokers, current cigarette smokers (including those. also smoking pipes or cigars), and current "other" $\overrightarrow{\vec{H}}$ smokers (those smoking only pipes or cigars or both).

Respiratory symptoms were defined from the answers to the questionnaire. Chronic bronchitis was defined as persistent cough (three months) with persis- $\frac{\vec{\omega}}{\omega}$ tent phlegm. Breathlessness grade 1 describes short- $\omega$ ness of breath when hurrying on level ground or $\vec{v}$ walking up a slight hill; grade 2 describes shortness of $\checkmark$ breath when walking with other people of similar age $\mathrm{O}$ on level ground; and grade 3 describes having to stopfor breath when walking at one's own pace on level ground. Recent chest illness describes a positive an- $\bar{\alpha}$ swer to, "During the past three years have you had? any chest illness which has kept you from your usual $\overrightarrow{0}$ activities for as much as a week?" and to "Did you bring up more phlegm than usual in any of these illnesses?" The number of these illnesses was assessed by the subsequent question, "Have you had more than one illness like this in the past three years?"

Results were analysed by tabulations and simple $\frac{\circ}{\square}$ statistical tests. In view of our reservations concerning $\vec{\Rightarrow}$ the use of predicted values of lung function derived from populations different from the one under study, predicted values for $F E V_{1}$ were derived not only from? the published predicted values of Cotes, ${ }^{20}$ but also from prediction equations that were so far as possible $\mathbb{\varnothing}$ appropriate to the study populations. For the telecom? workers predicted values of $\mathrm{FEV}_{1}$ according to age $\frac{}{3}$ and height were derived from 50 men among the study population who were lifelong non-smokers and who응 did not admit to respiratory symptoms. For the miners such a simple approach was not possible, $\frac{\circ}{5}$ because of the influence of dust exposure on FEV 1 , Data on the lifetime dust exposures for these men are?. being processed, and are not yet available. Prediction $N$ equations have, however, been derived from $451^{\circ}$ miners without respiratory symptoms or progressive $\mathcal{N}$ massive fibrosis among a group of 543 non-smoking $\omega$ faceworkers without PMF, described previously,, 0 from 20 collieries in Britain, six of which were in southe Wales and one of which is the subject of the present $\bar{\varnothing}$ study. A regression equation for $\mathrm{FEV}_{1}$ according to $\stackrel{?}{+}$ age, height, and dust exposure was derived for these $\overparen{T}$ men, and the fitted regression coefficients for age and $\stackrel{\vec{T}}{\vec{D}}$

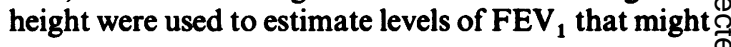


have been expected among the miners seen in the present study had they not been exposed to dust. This equation is referred to in this paper as the "miners' prediction equations." A more detailed description of this work is being published separately (M Jacobsen, personal communication).

\section{Results}

\section{POPULATION STUDIED}

A total of 458 miners and 228 telecom workers was studied, comprising 336 currently employed miners ( $87 \%$ of those selected) and 165 current telecom workers $(67 \%)$, and only 122 mining leavers $(33 \%)$ and 63 telecom leavers $(26 \%)$. Eighty five of the 371 selected mining leavers had died before the survey; thus the response among living ex-miners was $43 \%$. In view of the poor response of the leavers, comparisons of miners and telecom workers have been confined to men currently employed, relevant figures for the leavers being given as supporting information, without formal comparisons. The distribution of examined miners and telecom workers by age was similar (table 1), but the telecom workers tended, on average, to be about $3 \mathrm{~cm}$ taller than the miners (table 2).

\section{RESPIRATORY SYMPTOMS}

Respiratory symptoms were systematically much more commonly reported by currently employed miners than current telecom workers (table 2). For instance, the frequency of chronic bronchitis in current miners was $31 \%$ compared with $5 \%$ in the telecom workers. A similar (but not statistically significant) difference was seen even in the small number of non-smokers reporting chronic bronchitis. Large differences were also seen in the frequencies of reports of breathlessness - for instance, breathlessness grade 2 or more was reported by $32 \%$ of current miners but by only $2 \%$ of telecom workers; a similarly large and statistically significant difference was seen in the non-smokers. Recent chest illnesses were also reported much more frequently by the current miners $(20 \%)$ than by the telecom workers $(8 \%)$. Among the leavers similarly large differences between ex-miners and ex-telecom workers were seen.

The excess of chronic bronchitis among the current miners was present in younger as well as older menfor instance, $29 \%$ in men under $35,30 \%$ in men aged 35 to $44,35 \%$ in men aged $45-54$, and $29 \%$ in men over 55. Recent chest illness was also commonly reported by the younger miners; $20 \%$ (under 35 ), $19 \%$

Table 1 Age distribution of men examined

\begin{tabular}{|c|c|c|c|c|c|c|c|c|}
\hline & & \multicolumn{7}{|c|}{ Age group (years) } \\
\hline & & $25-34$ & $35-44$ & $45-54$ & $55-64$ & $65-74$ & $\geqslant 75$ & Total \\
\hline Currently employed & Miners & $77(23 \%)$ & $90(27 \%)$ & $96(29 \%)$ & $73(22 \%)$ & 0 & 0 & $336(100 \%)$ \\
\hline Leavers & $\begin{array}{l}\text { Telecom workers } \\
\text { Miners } \\
\text { Telecom workers }\end{array}$ & $\begin{array}{r}37(22 \%) \\
16(13 \%) \\
9(14 \%)\end{array}$ & $\begin{array}{r}45(27 \%) \\
16(13 \%) \\
7(11 \%)\end{array}$ & $\begin{array}{c}54(33 \%) \\
11(9 \%) \\
5(8 \%)\end{array}$ & $\begin{array}{l}29(18 \%) \\
37(30 \%) \\
15(24 \%)\end{array}$ & $\begin{array}{l}0 \\
39(32 \%) \\
23(37 \%)\end{array}$ & $\begin{array}{l}0 \\
3(2 \%) \\
4(6 \%)\end{array}$ & $\begin{array}{r}165(100 \%) \\
122(100 \%) \\
63(100 \%)\end{array}$ \\
\hline
\end{tabular}

ble 2 Frequencies of respiratory symptoms in miners and telecom workers. Cigarette smokers, other smokers, and ex-smokers have $n$ grouped together. $p$ Values indicate significance of differences between current miners and current telecom workers. Grades of pnoea correspond to the sequence of questions in the MRC questionnaire

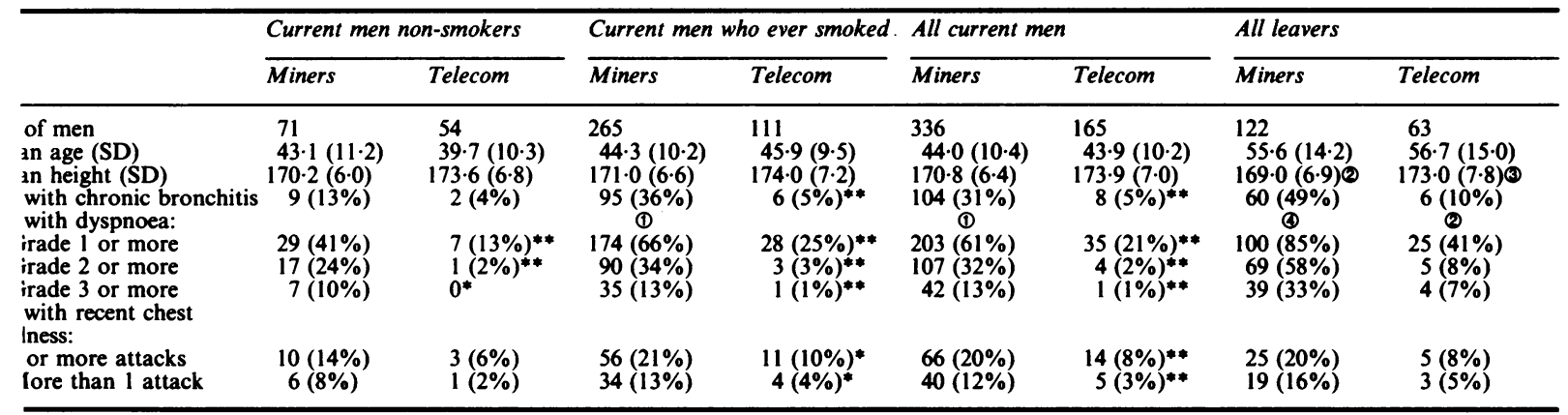

$\left.,<0.01,{ }^{*} 0.05>\mathrm{p}>0.01\right)$. Circled numbers indicate the number of men with missing data. 
(35-44), $16 \%$ (45-54), and $26 \%$ (over 55 ). The various grades of breathlessness were, however, strongly related to age.

\section{LUNG FUNCTION}

The prediction equations used for assessing the $\mathrm{FEV}_{1}$ are shown in table 3. The application of Cotes's predicted values to both miners and telecom workers (table 4) indicates that $20 \%$ of the current miners and $10 \%$ of the current telecom workers had an FEV below $80 \%$ predicted $(p<0.05)$. Four per cent of the miners and $1 \%$ of the telecom workers had an FEV less than $60 \%$ predicted; this difference could have arisen by chance one time in ten. The frequency of $\mathrm{FEV}_{1}<80 \%$ was less in the non-smokers but the differences between miners and telecom workers are still apparent; $13 \%$ of non-smoking miners had an $\mathrm{FEV}_{1}$ less than $80 \%$ predicted, compared with $7 \%$ of telecom workers. The differences for men who had smoked are similarly striking. Among the leavers, higher frequencies of low $\mathrm{FEV}_{1}$ are seen, and the differences between miners and telecom workers are large.

The application of the miners' prediction equations to the miners and internal predictions to the telecom workers tended to classify more men in both groups

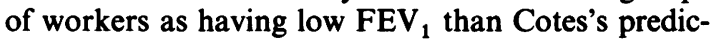
tion equations (table 4). Nevertheless, substantial differences between miners and telecom workers were again shown.
The classifications of the chest radiographs indicated that 11 of the current miners $(3.3 \%)$ and 18 of the leavers had progressive massive fibrosis (PMF). By Cotes's criteria, five of the current men with PMF had an $\mathrm{FEV}_{1}$ less than $80 \%$ predicted and three less than $60 \%$. Two of the leavers with PMF had missing $\mathrm{FEV}_{1}$, and 13 of the remaining 16 men had an FEV less than $80 \%$, and eight less than $60 \%$ predicted. Even after exclusion of men with PMF the differences in function between miners and telecom workers were substantial.

\section{Discussion}

We have found large differences in the frequencies of respiratory symptoms reported by currently employed miners in one colliery and nearby telecom workers.

Answers to respiratory symptoms questionnaires might be influenced by social and professional atti- $\searrow$ tudes, but the differences we found in the number of $O$ men with low lung function in the two groups suggest that the differences in respiratory symptoms were genuine. We recognise the difficulties in applying prediction equations for lung function derived from other populations, and in this work we have used several prediction equations, some of which were as appropriate to the populations under study as we could contrive, and found that whichever predictions were used, similar large differences between miners and telecom workers were shown.

Table 3 Coefficients for the prediction equations for FEV (litres) used in this paper

\begin{tabular}{lllc}
\hline Coefficient prediction equations & Age (years) & Height $(\mathrm{cm})$ & Dust exposure $\left(\mathrm{gh} / \mathrm{m}^{\mathbf{3}}\right)$ \\
\hline Cotes $^{20}$ & -0.031 & +0.0362 & - \\
Miners & -0.03532 & +0.03773 & -1.41 \\
Telecom & -0.046979 & +0.05809 & -1.39542 \\
\hline
\end{tabular}

*Dust exposure was set at zero for the predictions.

Table 4 Number of men with low FEV, according to percentages of Cotes's predictions, miners predictions, and telecom internal pre dicted values. Four miners and five telecommunications men are excluded because of inadequate data

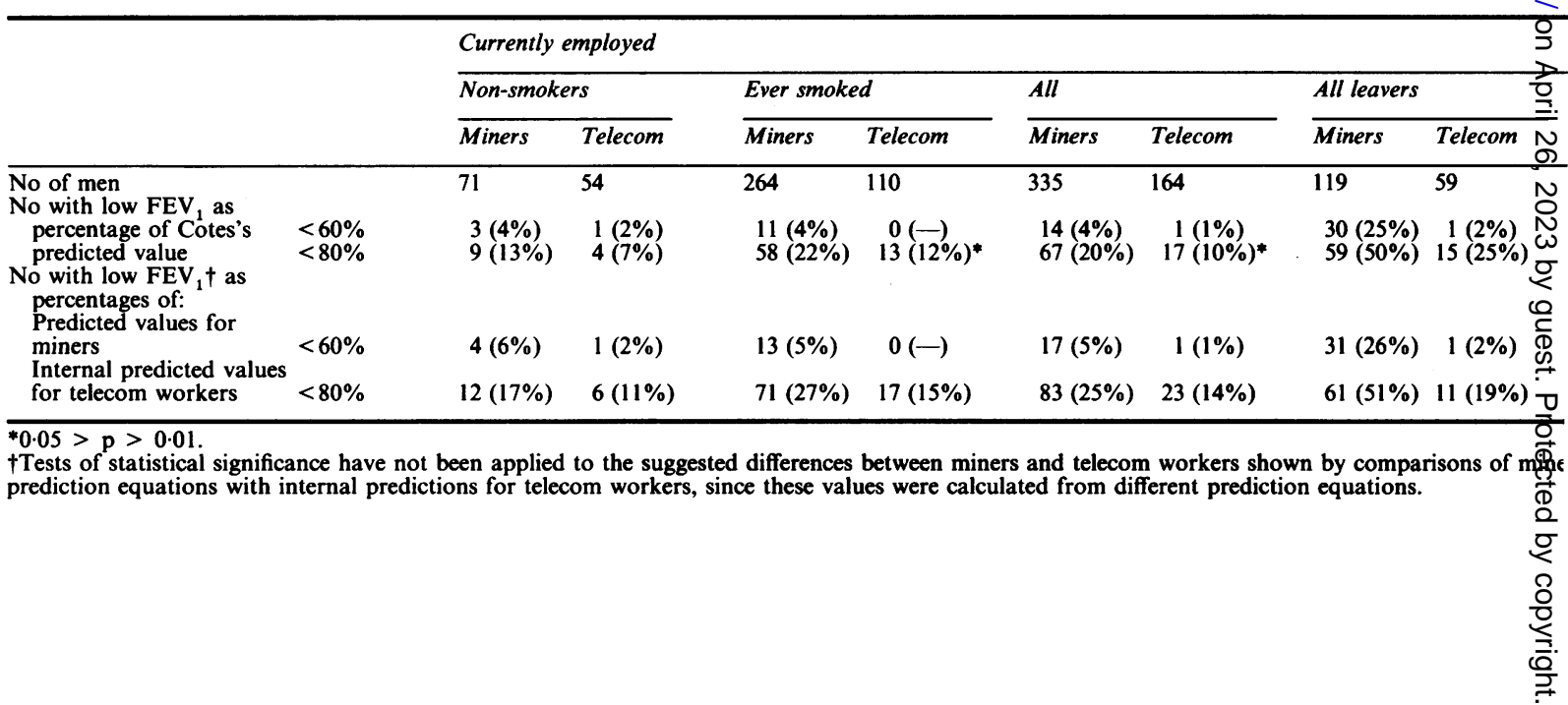


The response from men who had left their respective industries (despite considerable efforts to recruit them) were too low to permit definite conclusions to be drawn about the respiratory health of these populations. For what it is worth, the results for these men also tend to suggest greater ill health among the ex-miners than the ex-telecom men. The major factors affecting response were moving away and refusals.

Whereas it would be impossible to find an exactly socially comparable group of men to compare with miners, telecom workers were chosen as they were thought to provide a reasonable comparison. Electrical fitters have in the past been considered by others to be a reasonably socially comparable group. ${ }^{21}$ In the event an average difference of $3 \mathrm{~cm}$ in height tends to suggest quite a large social or ethnic difference between the groups, unless the nature of either of the jobs encourages men of a certain height to join. In this respect differences of height between miners and nonminers have been observed elsewhere, miners tending to be shorter. ${ }^{22}$ In future studies we shall additionally be including other occupational groups.

The differences found between the miners and telecom workers could be the consequence, among other factors, of exposure to respirable dust, though not necessarily to current levels. In older men the excess of respiratory disease might result from exposure to higher dust concentrations occurring before 1970 , though this is less likely to be the explanation for the excess of chronic bronchitis in the younger men. Historically, also, south Wales miners have had a higher prevalence of pneumoconiosis than those in other areas (and still do), ${ }^{16}$ and the findings in this colliery population are not necessarily representative of British coalminers generally. An analysis in progress of the influences of current and past dust concentrations, smoking, and other non-occupational factors should indicate what measures to improve the respiratory health of these miners are required in the fields of public health, health education, or improvements in conditions at work.

We thank the miners who took part and the management and men of British Telecom for their generous cooperation.

This work was supported by the National Coal Board of Great Britain and the Commission of the European Communities (Contract No 7248-15-019).
References

${ }^{1}$ Carpenter RG, Cochrane AL, Gilson JC, Higgins ITT. The relationship between ventilatory capacity and simple pneumoconiosis in coalworkers. $\mathrm{Br} J$ Ind Med 1956;13:116-76.

${ }^{2}$ Higgins ITT, Oldham PD, Cochrane AL, Gilson JC. Respiratory symptoms and pulmonary disability in an industrial town. Survey of a random sample of the population. $\mathrm{Br}$ Med $\mathrm{J}$ 1956;ii:904-10.

${ }^{3}$ Higgins ITT, Cochrane AL, Gilson JC, Wood CH. Population studies of chronic respiratory disease; a comparison of miners, foundry workers and others in Stavely, Derbyshire. Br J Ind Med 1959;16:255-68.

${ }^{4}$ Higgins ITT, Cochrane AL. Chronic respiratory disease in a random sample of men and women in the Rhondda Fach in 1958. Br J Ind Med 1961;18:93-102.

${ }^{5}$ Lowe CR, Khosla T. Chronic bronchitis in ex-coal miners working in the steel industry. Br J Ind Med 1972;29:45-9.

${ }^{6}$ Higgins ITT. Occupational factors in chronic bronchitis and emphysema. In: Orie NGN, Van der Lende R, eds. Bronchitis III; proceedings of the third international symposium on bronchitis, Groningen, the Netherlands 1969. Springfield, Ill: Charles C Thomas, 1970.

${ }^{7}$ Rae S, Walker DD, Attfield MD. Chronic bronchitis and dust exposure in British coalminers. In: Walton WH, ed. Inhaled particles III. Old Woking, Surrey: Unwin Bros, 1971:883-94.

${ }^{8}$ Kibelstis JA, Morgan EJ, Reger R, Lapp NL, Seaton A, Morgan WKC. Prevalence of bronchitis and airway obstruction in American bituminous coal miners. Am Rev Respir Dis 1973;108:886-93.

${ }^{9}$ Rogan JM, Attfield MD, Jacobsen M, Rae S, Walker DD, Walton WH. Role of dust in the working environment in development of chronic bronchitis in British coal miners. $\mathrm{Br} J$ Ind Med 1973;30:217-26.

${ }^{10}$ Hankinson JL, Reger RB, Fairman RP, Lapp NL, Morgan WKC. Factors influencing expiratory flow rates in coal miners. In: Walton WH, ed. Inhaled particles IV. Oxford: Pergamon Press, 1977:737-55.

${ }^{11}$ Reichel G, Ulmer WI. In: Chronic bronchitis and occupational dust exposure. Deutsche Forschungmeinschaft. Boppard: Hardold Boldt Verlag KG, 1978;224-91.

${ }^{12}$ Soutar CA, Hurley JF, Gurr DC. The relationship between dust exposure and lung function in miners and ex-miners. In: $V I$ international pneumoconiosis conference, Bochum 1983. Geneva: International Labour Organisation, 1984:390-6.

${ }^{13}$ Love RG, Miller BG. Longitudinal study of lung function in coal miners. Thorax 1982;37:193-7.

${ }^{14}$ Health and Safety. Mines and quarries. The coal miners (respirable dust) regulations 1975. London: HMSO, 1975. (SI No 1433.)

${ }^{15} \mathrm{Health}$ and Safety. Mines and quarries. The coal mines (respirable dust) (amendment) regulations 1978. London: HMSO, 1978. (SI No 807.)

${ }^{16}$ National Coal Board Medical Service. Annual report 1983-4. London: $N C B$.

${ }^{17}$ Jacobsen M. Coalworkers' pneumoconiosis: results from epidemiological studies in Britain. In: VI international pneumoconiosis conference, Bochum 1983. Geneva: International Labour Office, 1984:92-102.

${ }^{18}$ Medical Research Council. Report of the working party on research into chronic bronchitis. London: Medical Research Council, 1976.

${ }^{19}$ International Labour Office. Guidelines for the use of ILO international classification of radiographs of pneumoconiosis. Geneva: ILO, 1980. (Occupational safety and health series, No 22 (rev 80).)

${ }^{20}$ Cotes JE. Lung function: assessment and application in medicine. 4th ed. Oxford: Blackwell Scientific Publication, 1979.

${ }^{21}$ Lowe CR. Chronic bronchitis and occupation. Proc $R$ Soc Med 1968;61:98-102.

${ }^{22}$ Enterline PE. The effects of occupation on chronic respiratory disease. Arch Environ Health 1967;14:189-200. 